no. $64-37$

\author{
United States \\ Department of the Interior \\ Geological Survey
}

SELECTION OF METAL COMPONENTS FOR LONG-TERM DEVELOPMENT

OF EGYPT'S CORROSIVE GROUND WATERS

Prepared by the United States Geological Survey

in cooperation with the Egyptian General Desert Organization under the auspices of

the United States Agency for International Development

Mission to the United Arab Republic 


\section{Selection of Metal Components for Long-term Development of Egypt's Corrosive Ground Waters}

By

Frank E. Clarke

U. S. Geological Survey

Cairo, Egypt, UAR July 1964 


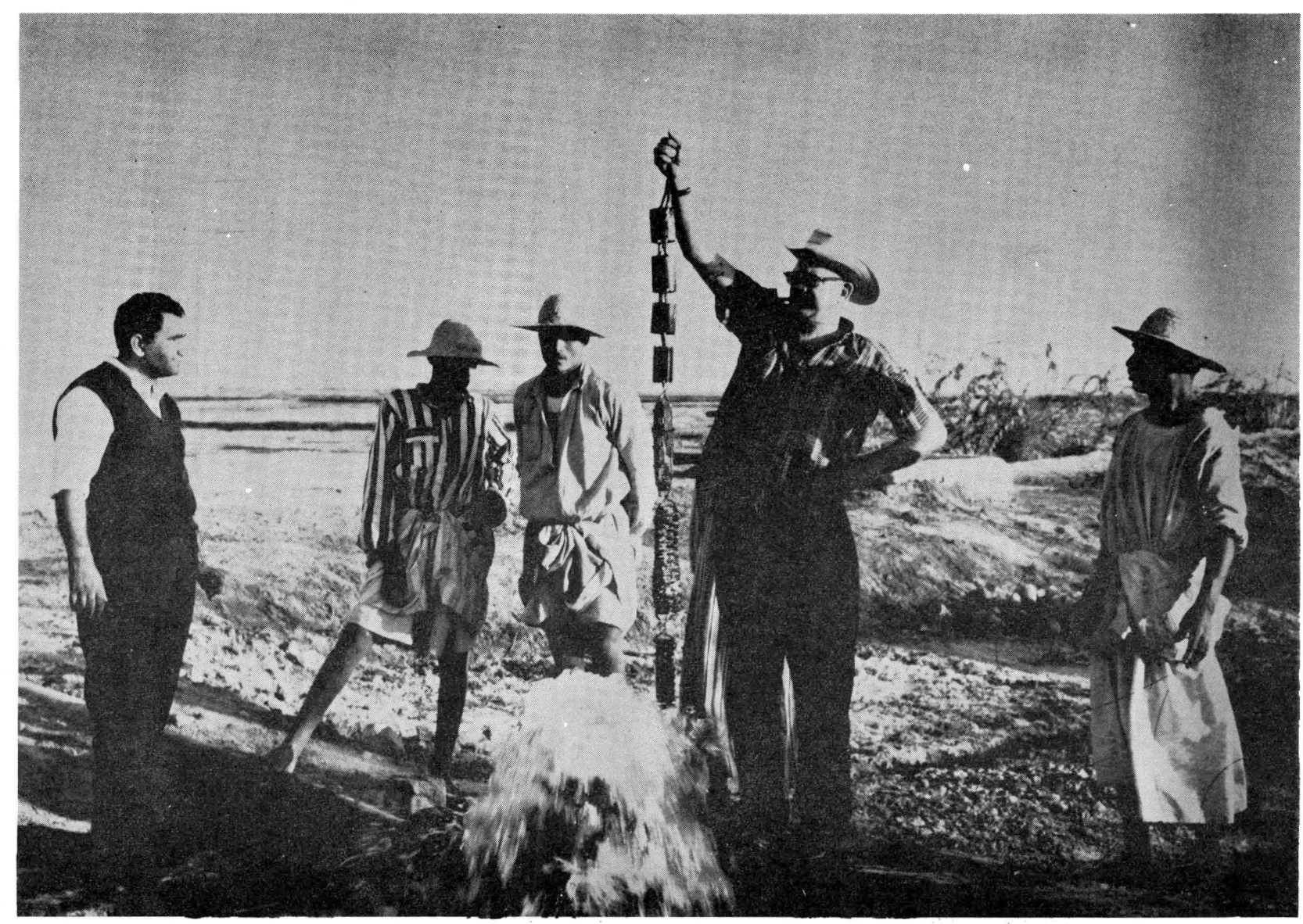

Frontispiece.--Ralph Fry, USAID, and George Tewfik Fahmy, EGDDO, removing specimens from Mut No. 2 Well, Dakhla Depression. 
Contents

Page

Abstract . . . . . . . . . . . . . . .

Acknowledgements . . . . . . . . . . . .

Introduction . . . . . . . . . . . . . .

Metal Iife in Kharga Well Waters . . . . . . . 5

Mild Steel . . . . . . . . . . . 5

Aluminum ....................... 11

Mone1 . . . . . . . . . . . 14

Stainless Steel . . . . . . . . . 14

Incoloy 800 . . . . . . . . . . . . 15

Metal Life in Dakhla Well Waters . . . . . . . 17

Mild Steel . . . . . . . . . . 17

Aluminum .................... 21

Monel ................... 23

Stainless Steel . . . . . . . . 26

Incoloy 800 . • . . . . . . . . . . 27

Significance of Long-term Corrosion Tests . . . . . 28

Direction of Future Studies . . . . . . . . 32

Conclusions . . . . . . . . . . . . 35

Recommendations . . . . . . . . . . 37

References . . . . . . . . . . . . 39 
Frontispiece.--Ralph Fry, USAID, and George Tewfik Fahmy, EGDDO, removing specimens from Mut No. 2 Well, Dakhla Depression . . . . . . . . . . II

Figure 1.--Steel bridge-slot screen after two years in Kharga No. la well - I.25X . . . . . . . 7

Figure 2.m-Pitted steel casing specimen, Kharga No. la Well, two years' exposure - 1.25X • • • • • • • 9

Figure 3.--Corrosion rate curves, mild steel, Kharga Depression ............. 10

Figure 4.--Corrosion rate curves, aluminum probes, Kharga Depression ............. 13

Figure 5.--Corrosion rate curves, Incoloy probes, Kharga and Dakhla Depressions ......... 16

Figure 6.--Steel bottom-hole specimen, 11 months' exposure, Mut No. 2 Well - 1.75X ........... 19

Figure 7.--Corrosion rate curves, mild steel probes, Dakhla Depression ............ 20

Figure 8.--Aluminum bottom-hole specimen, 11 months' exposure, Mut No. 2 Well - I.25X .......... 22

Figure 9.--Corrosion rate curves, aluminum probes, Dakhla Depression .......... 24

Figure 10.--Monel bottom-hole specimen, Mut No. 2 Well . • • 25 
SELECTION OF METAL COMPONENTS FOR LONG-TERM DEVELOPMENT

OF EGYPT'S CORROSIVE GROUND WATERS

By

Frank E. Clarke

\begin{abstract}
Several years of systematic corrosion study on ground waters of Egypt's Western Desert have confirmed predictions that mild steel is a poor well-construction material for practically every location tested; that aluminum, while generally many times as resistant as mild steel, is subject to objectionable pitting in certain locations; and that nickel-bearing alloys, such as Type 304 stainless steel and nickel-chromium steel (Incoloy 800), are virtually unaffected by the desert's aggressive ground waters. Limited experience with Monel shows that this nickel-copper alloy corrodes very slowly and uniformly despite the presence of sulfide compounds in the water.

These results leave little doubt that mild steel should be avoided in fabricating sensitive well parts such as screens, perforated casings, and well-control valves, particularly when long-term service is important. High-strength, corrosion-resisting aluminum alloys, such as Types 6061 and 6063 or AA5083 (Canadian CAD54S), would last several times as long as mild steel in most of the wells. Since the minimum cost of aluminum tubing is $1 \frac{1}{2}$ to 2 times the cost of steel, it should be suitable for use as screen or perforated casing in any wells which are likely to be abandoned when general pumping begins.
\end{abstract}


Type 304 stainless steel appears to be the most economically feasible material from which to make high-strength, essentially permanent metal screen. However, the economic advantage of using this relatively expensive alloy (minimum cost factor $2 \frac{1}{2}$ to 3 ) will depend on the life expectancies of the well for which it is being considered. Transition from relatively small diameter wells, which are not suitable for pumping, to larger diameter, relatively permanent pumping installations will increase the attractiveness of this durable alloy. The performance of Monel suggests that copper-bearing alloys of intermediate corrosion resistances are adequate for use in readily accessible well-head valves and pump parts. Field tests and further corrosion studies will be required to determine the most economical type of pump installation. Plans for these tests have been made. 
Information and assistance provided by USAID personnel, Raymond W. Sundstrom and Paul P. Bieber, and by Chemistry Section personnel of the Egyptian General Desert Development Organization (EGDDO), particularly George Tewfik Fahmy, contributed significantly to this third field study of water qualities and corrosion characteristics. The laboratory data collected by the EGDDO laboratory during the past year were helpful in evaluating new corrosionspecimen performance data. The continued interest, encouragement, and hospitality of all USAID and EGDDO personnel is gratefully ackrowledged. 
Introduction

For the past three years, the corrosion characteristics of Western Desert well waters have been studied by physical tests, chemical analyses, electrical-resistance-type corrosion probes, and a variety of metallic corrosion specimens exposed to the flowing well waters. The study was based on the assumption that well screens and casings are required, since this part of the program is not concerned with determining practicability of open-hole operation.

The purpose of the latest field study described herein was to determine the long-term performance of corrosion probes and metal specimens in several wells of Kharga and Dakhla Depressions, and from these observations to revise as necessary earlier tentative conclusions regarding the materials best suited for use in long-term development of Western Desert ground waters. The observations are presented separately for performance of the several construction materials in Kharga and Dakhla Depressions. They combine observations made on several occasions during the period March 1962 to March 1964. Only metallic components are discussed. Corrosion mechanisms and nonmetallic construction material were covered in earlier reports (Clarke, 1962 and 1963). 
Metal Life in Kharga Well Waters

Mild steel.--The mild steel specimens used in Kharga Depression wells included both surface-line specimens and corrosion probes of the type discussed by Clarke (1962 and 1963). The surface-line specimens included sections of bridge-slotted screens and drillperforated $\frac{1}{4}$-inch-thick steel casings (5/8-inch holes). These were installed in the horizontal discharge lines of Kharga No. la Replacement Well just north of the old town of Kharga. An elbow at the end of the discharge line was turned upward to insure continuous submergence of the specimens in the flowing water. All corrosion probes consisted of 40-mil (0.04-inch) diameter wire inserted through special threaded adapters in the vertical well casings just above ground level.

The screen sections and drilled casing specimens originally were installed on March 10, 1962, and thus had been in continuous service for approximately 24 months at the time of this examination except for a few minutes each in 1962 and 1963 when they were removed for inspection.

Mild steel corrosion probes were installed in Kharga, Nasser, Boulaq and Baris wells on several dates in 1962 and 1963. All of these specimens failed in 7 months or less, except the specimen in Nasser No. 3 Well, which lasted 13 months. All had failed prior to this final inspection. Several were inspected and reported in the preceding report (Clarke, 1963). 
When inspected on March 2, 1964, after two years in the discharge line of Kharga No. la Well, the black-iron bridge-slotted screen specimen still was completely covered with black deposit containing elastic hemispherical tubercles over localized pits. The coating consisted of residue of the originalbitumastic paint plus a soft black film of iron corrosion product. X-ray diffraction analysis showed this to be primarily $\mathrm{Fe}_{9} \mathrm{~S}_{8}$. The pits penetrated the $1 / 8$-inch tube wall to a maximum depth of slightly over 50 percent. The original porous black organic coating obviously had offered little protection to the metal. Figure $I$ shows an enlarged photograph of a section of

Figure 1.--Steel bridge-slot screen after two years in Kharga No. la well - 1.25X.

this bridge-slotted screen after partial removal of the coating and corrosion product down to the pitted base metal. As observed in previous inspections, damage seemed to be most severe on the raised bridge pieces of the screen, presumably because of accentuation by cold-working effects in the metal.

The test section of drilled casing also was uniformly black with corrosion products (no organic coating used) and contained numerous corrosion tubercles or blisters with relatively flat cross-sectional profiles. The cut ends of the cylinder retained the saw marks, but, as in previous inspections, these flaked away to show considerable subsurface damage, indicating a corrosion penetration phenomenon. 


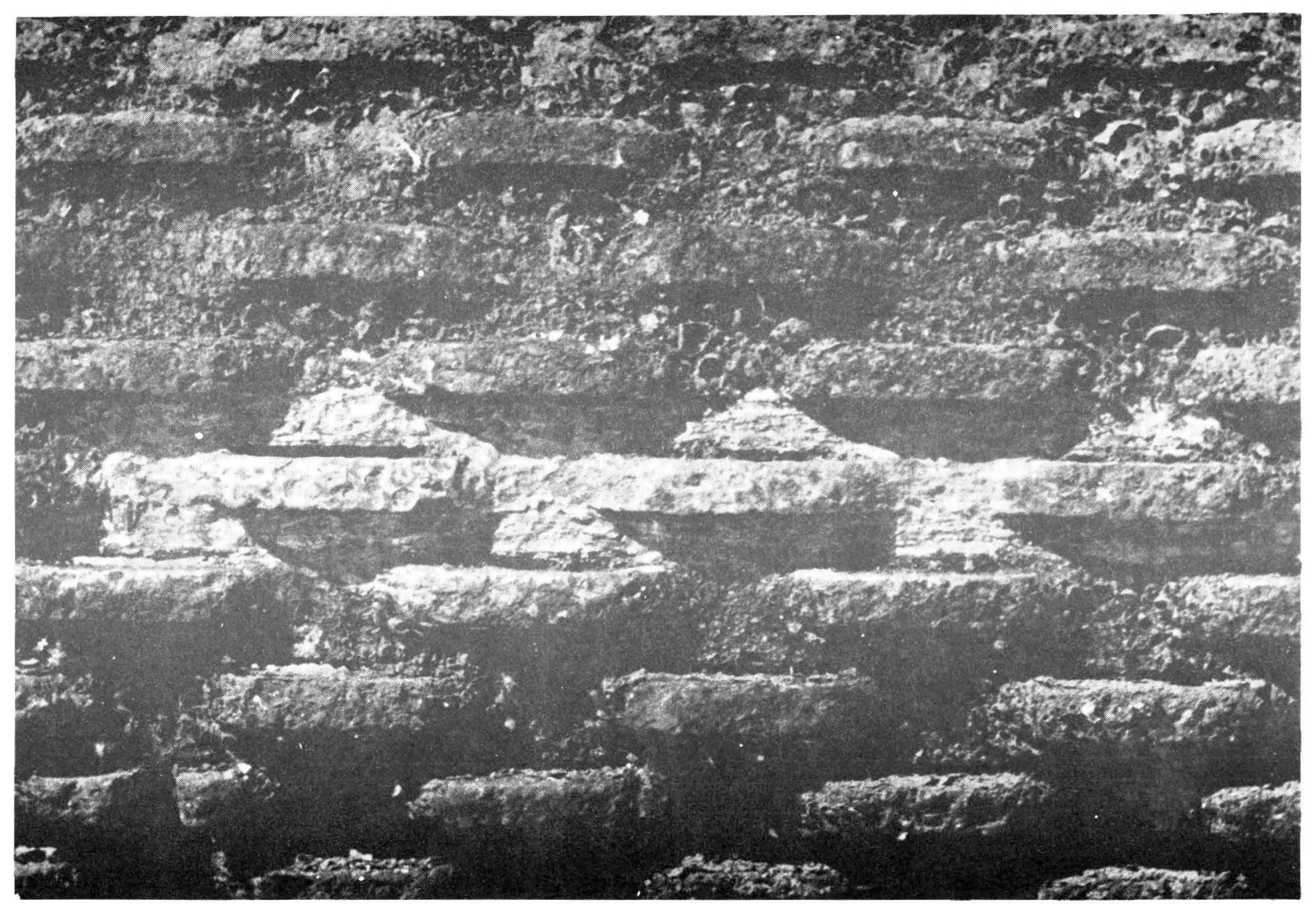

Figure 1.--Steel bridge-slot screen after two years in Kharga No. la Well - 1.25X. 
Such damage is characteristic of sulfide attack. In this specimen, as in the bridge-slotted screen, the maximum depth of penetration appears to be more than $1 / 16$ inch. Figure 2 shows a corroded area

Figure 2.--Pitted steel casing specimen, Kharga No. la Well, two years' exposure - $1.25 \mathrm{X}$.

of the perforated casing scraped down to bare metal.

Figure 3 is a plot of corrosion rate curves for the mild steel

Figure 3.--Corrosion rate curves, mild steel, Kharga Depression.

probes in five wells scattered over the length of Kharga Depression. A typical corrosion rate curve for stainless steel (Type 304), and maximum and minimum rate curves for aluminum in the same depression (not the same wells) are included for comparison. With the exception of the steel probe in Nasser No. 3 Well, all of these curves for mild steel showed extremely steep slopes as evidence of very rapid corrosion, and all of the steel specimens failed in relatively short periods of time. The anomaly in Nasser No. 3 Well has not yet been checked with either a surface line specimen or another corrosion probe. However, the erratic alternation between low and high corrosion rates of a mild steel probe in nearby Nasser No. 1 Well suggests that damage to mild steel is, in fact, less severe in the Nasser area, at least as judged from these specimens exposed to mixed waters discharging from the several water horizons. The considerably higher average corrosion 


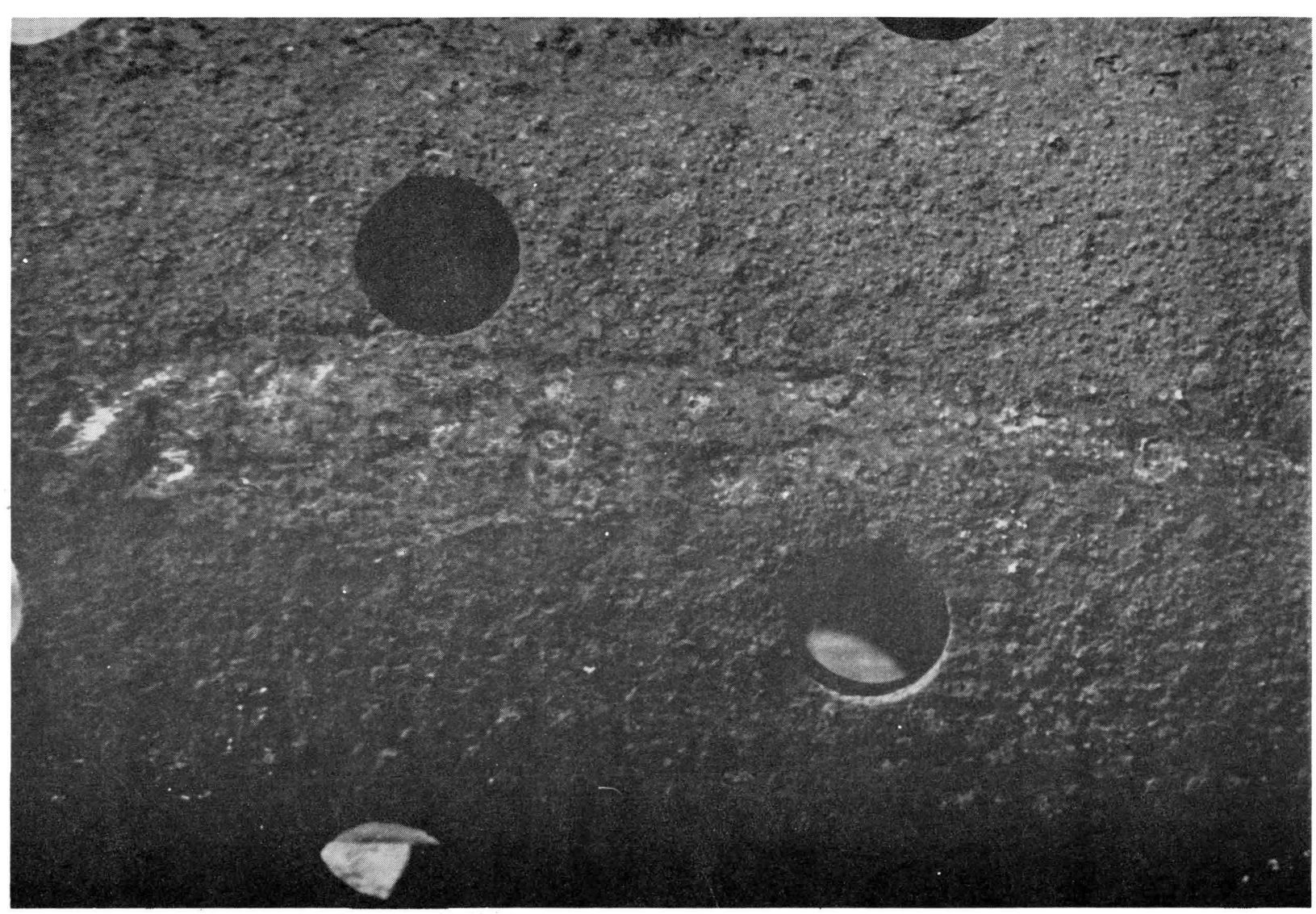

Figure 2.--Pitted steel casing specimen, Kharga No. la Well, two years' exposure - $1.25 \mathrm{X}$. 


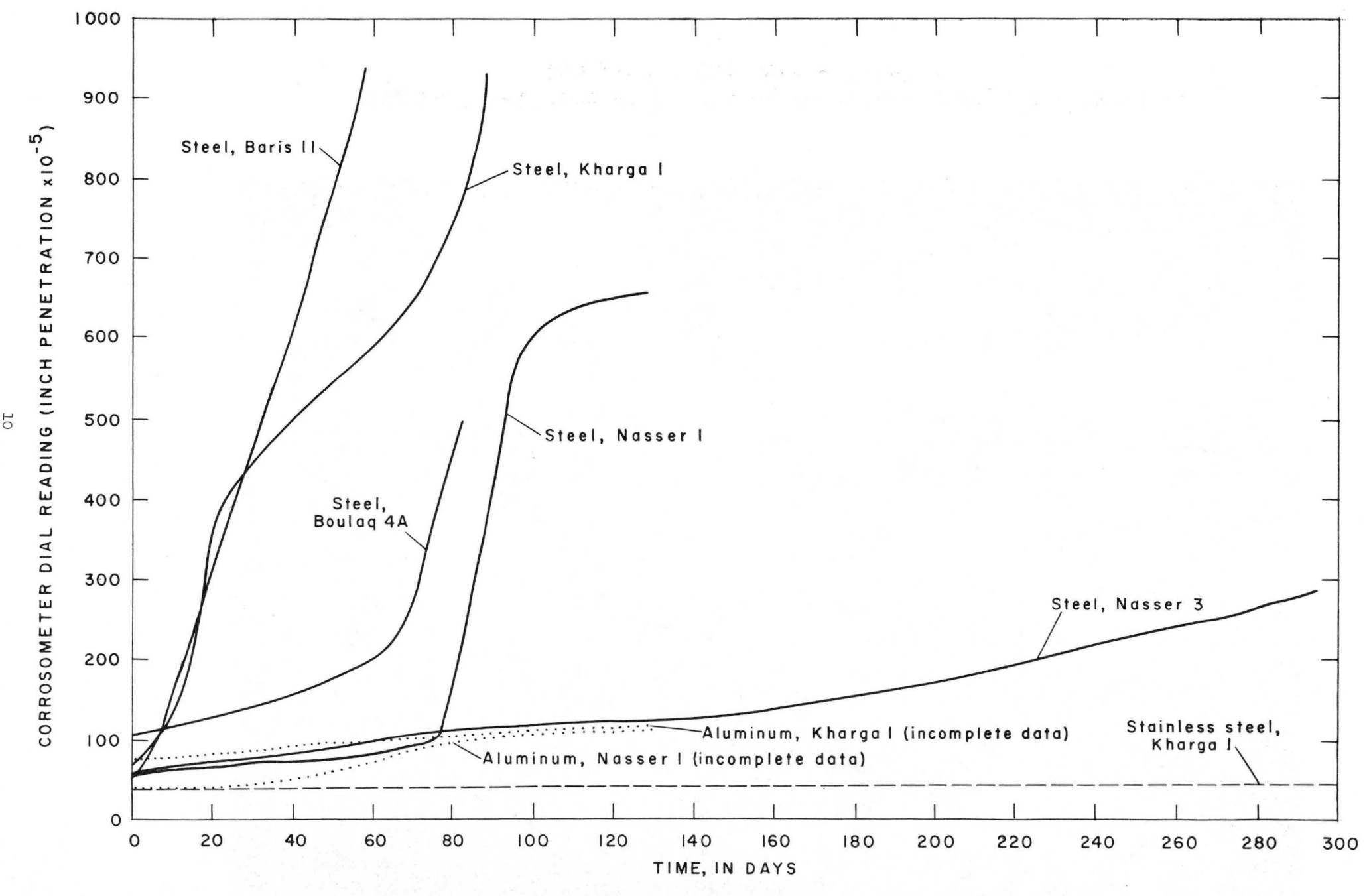

Figure 3.--Corrosion rate curves, mild steel, Kharga Depression. 
rate in Nasser No. 1 well, which is only a few yards away and a few hundred feet different in depth, shows that it would be hazardous to place undue significance on this single instance of encouraging behavior for mild steel. It also suggests pertinent variations in corrosion characteristics of the several aquifers which are being integrated in the discharges of Kharga Depression wells.

Excepting the unusual behavior of the probe in Nasser No. I Well, average corrosion rates for the steel probes ranged from 0.017 to 0.08 inches penetration per year. All of these rates are in the range which would be considered intolerable for long-life well service. Aluminum.-.The single large aluminum specimen installed in Kharga Depression was located in the horizontal discharge line of Kharga No. Ia Well. This was a section of $\frac{1}{4}$-inch-thick soft aluminum bridgeslotted screen of European origin. On removal from the line after 24 months, its surface contained a thin superficial film of black deposit (iron compounds) which brushed away readily to show the original mill marks and scars. Fresh-cut ends of the specimen showed a few white mounds of aluminum hydroxide (hydrated aluminum oxide, $\mathrm{Al}_{2} \mathrm{O}_{3} \cdot 3 \mathrm{H}_{2} \mathrm{O}$ ) corrosion deposits covering superficially etched areas. However, at least 99 percent of this screen still was in essentially original condition despite its long period of exposure, and there was no corrosion beyond superficial depth.

The corrosion resistance of aluminum alloy, as indicated by corrosion probes in several vertical well casings of Kharga Depression was considerably better than that of mild steel in the same wells. 
However, significant variation was evident from well to well. This is apparent in the plot of the corrosion curves for aluminum in figure 4. The slopes of the curves for Kharga No. la Well, Nasser Figure 4.--Corrosion rate curves, aluminum probes, Kharga Depression. No. 3 Well, and Baris No. II Well were uniformly low, indicating corrosion rates from 0.0012 to 0.0019 inches per year. On the other hand the rate curve for the probe in Nasser No. 1 Well was somewhat steeper throughout the exposure period prior to its failure from mechanical damage after approximately 300 days. The specimen in Boulaq No. 4 a Well yielded a resistance reading that indicated complete severance of the probe wire in only 237 days. Data were not available for preparing a curve. Comparison plots for steel and stainless steel included in this same figure for reference show that mild steel probes exposed to the same waters failed in less than half the time required for failure of aluminum probes. The performance of stainless steel was markedly better in every case.

In considering the performance of aluminum, it is also important to note that the 40-mil probe wires accentuate the sensitivity of the alloy. The rather small diameter of the probe's wire loop may cause it to vibrate considerably if flow is unsteady, and this can break the protective oxide film on which the wire's corrosion resistance depends. Early failure of the wire near its junction with the probe's cylinder is evidence of this effect. 


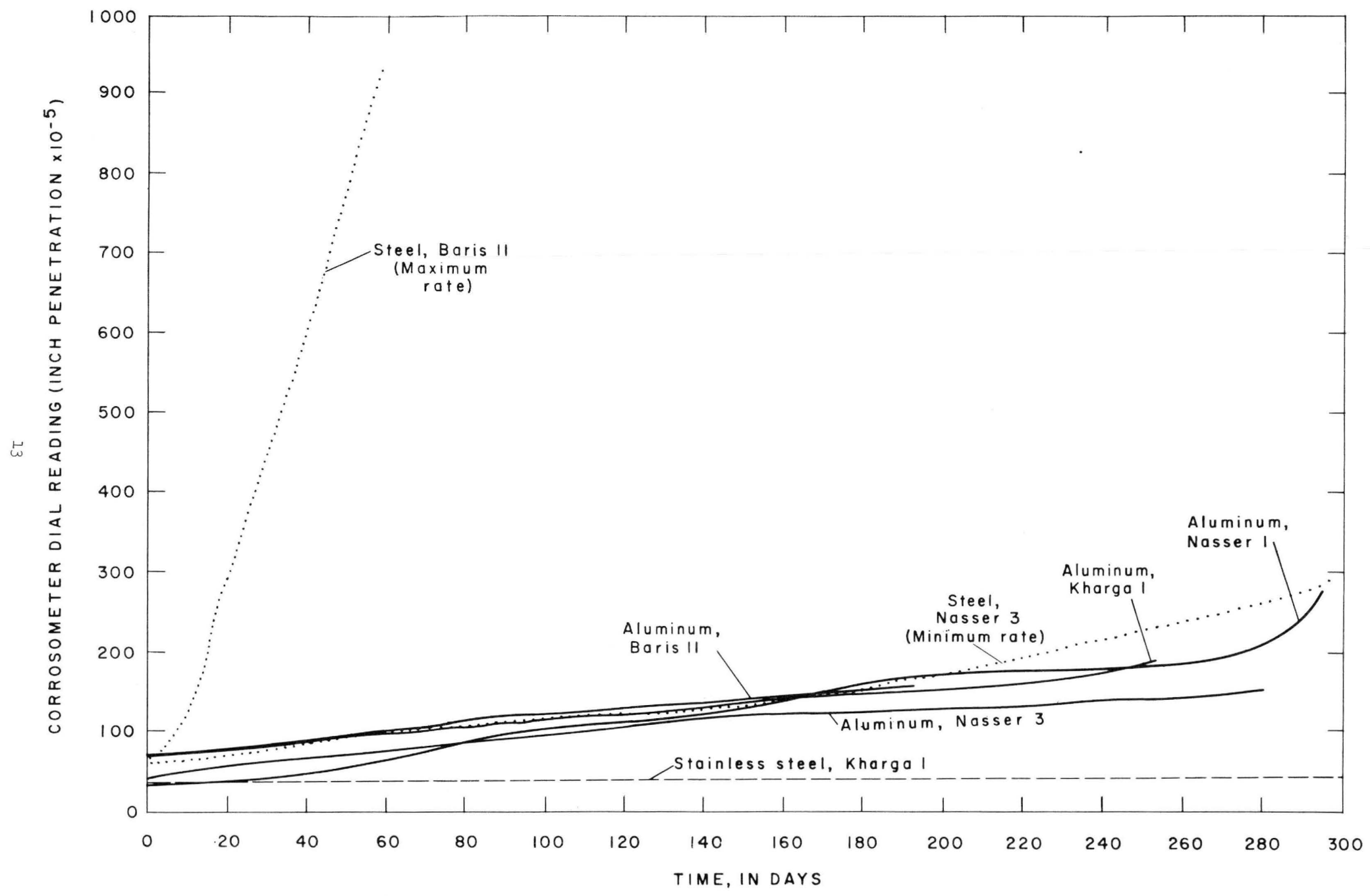

Figure 4.--Corrosion rate curves, aluminum probes, Kharga Depression. 
Incidentally, the rather sharp break in the aluminum corrosion curve of Nasser No. I Well resulted from damage to the corrosion probe during installation of a current meter for other test work. Monel..--Corrosion probes in Baris No. 11, Nasser No. 1, and Boulaq No. 4a Wells were the only Monel specimens exposed in Kharga Depression. Exposure periods prior to this examination were 208 days, 67 days, and 131 days respectively. Performance was uniformly good. The highest corrosion rate occurred in Nasser No. I ( 0.0013 inch per year). The rates in Baris No. 11 and Boulaq No. $4 a$ were only 0.00018 and 0.00022 , respectively. All rates were below the 0.002 ipy value which generally is considered acceptable performance. In every case the corrosion mechanism appeared to be the same and to consist of partial surface de-nickeling of the speeimen. This produced a golden discoloration and a sloughing off of microscopic layers with a resulting gradual reduction in specimen diameter. This performance is markedly better than the average performance of mild steel; it equals the best performance of aluminum and approaches the excellent performance of stainless steel.

Stainless steel.--The single surface-line specimen of wire-wrapped stainless steel screen exposed in Kharga No. la Well contained scattered patches of black surface film which turned yellow on drying (iron compounds). Flushing this film away showed original mill marks and bright surface as evidence that there was essentially no corrosion after two years of exposure. The 40-mil-diameter stainless steel 
probe wire in the vertical casing of this well still was yielding about the same resistance reading as when it originally was installed. The corrosion rate curve for this probe is shown on other curves for Kharga Depression (figs. 3 to 5) as base-line index of excellent performance. While time and availability of corrosion test equipment have not yet permitted trial of stainless steel in other Kharga Depression wells, the extremely low rate of corrosion in Kharga No. la Well, and similar performance in Dakhla Depression (discussed later in this report) suggest that this alloy is essentially impervious to the Western Desert ground waters thus far tested.

Incoloy 800.--This super-corrosion-resisting, nickel-chromium-steel alloy mentioned in the previous reports on the Western Desert was made available as tubular specimens and corrosion probe wire rather late in the program and thus was tried in only one well of Kharga Depression (Nasser No. I Well) up to the date of this inspection. The extremely flat corrosion rate curve for this probe is shown in figure 5 .

Figure 5.--Corrosion rate curves, Incoloy probes, Kharga and Dakhla Depressions.

The slope of the curve over a 223-day period actually is negative, indicating no change within sensitivity limitations of test equipment. It is pertinent that this well caused extremely high rates of corrosion on mild steel, and a relatively high rate of corrosion on the more resistant aluminum alloy. Thus, it would appear that Incoloy, like stainless steel, is quite impervious to Western Desert ground waters, as predicted on the basis of theoretical considerations. 


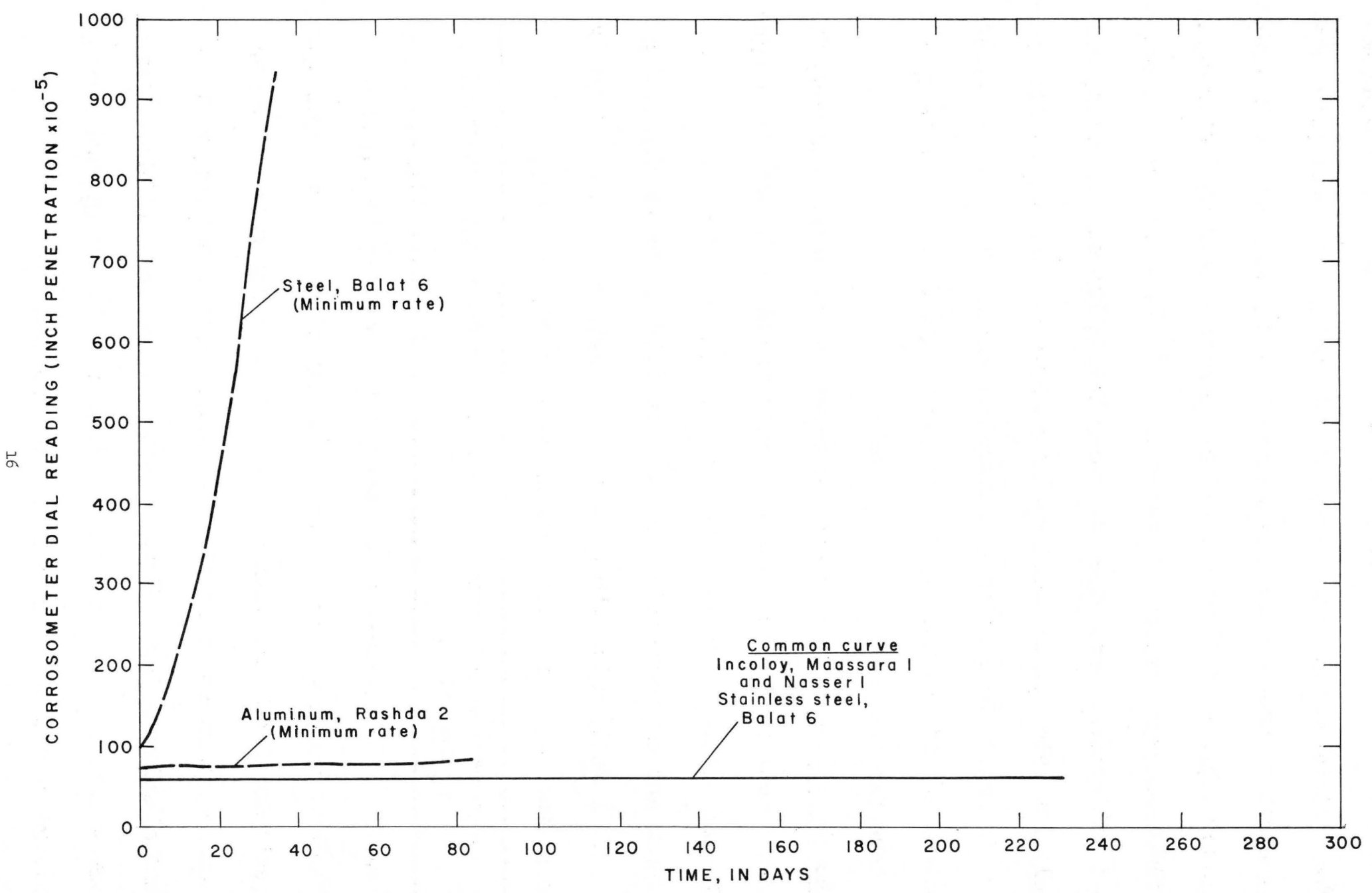

Figure 5.--Corrosion rate curves, Incoloy probes, Kharga and Dakhla Depressions. 
Metal Life in Dakhla Well Waters

In this desert depression, metal life studies also were made with corrosion probes; surface line specimens, including sections of well screen and perforated casing; and bottom-hole specimens of the latter type.

Mild steel.--Mild steel surface line specimens were tried only in Mut No. I Well. An earlier report (Clarke, 1963) presented data and photographs to illustrate the devastating effects of this well water on mild steel specimens. In the present instance, repeat specimens of mild steel installed in May 1963 and removed on March 3, 1964, showed the same type of heavy black corrosion deposits and deep corrosion pits reported in the earlier publication. Analysis of the deposit by $\mathrm{X}$-ray diffraction showed it to be primarily magnetite $\left(\mathrm{Fe}_{3} \mathrm{O}_{4}\right)$ with a minor amount of $\gamma \mathrm{FeOOH}$. The latter undoubtedly resulted from atmospheric attack after removing the specimens from the line. The absence of sulfide deposits agrees with the absence of sulfide in the well water.

The bottom-hole specimens of mild steel (and other alloys) were suspended near the top of the screen in Mut No. 2 Well approximately 1100 feet below land surface on April 19, 1963. The bottom-most specimen of this string, to which a sustaining weight was attached originally was a short section of 6 -inch-diameter, $\frac{1}{4}$-inch-thick perforated steel casing. Immediately above this, a section of bridge-slotted mild steel, flattened into an ellipse, was attached by means of a wire loop insulated with plastic tubing. During the 
ll-month exposure prior to this inspection, the bridge-slotted specimen corrodea completely in two at its lower apex, dropping the bottom specimen and the weight. Careful examination of the $1 / 8-i n c h-t h i c k$ bridge-slotted specimen showed an overall reduction in wall thickness of approximately 50 percent. The leading end (bottom) of the specimen showed the most serious damage (fig. 6) as evidence that velocity and

Figure 6.--Steel bottom-hole specimen, 11 months' exposure, Mut No. 2 Well - 1.75X.

impingement effects discussed in an earlier publication (Clarke, 1962) played important roles in the damage. In this case, as with the steel specimens in Mut No. I Well and Kharga No. la Well, the most serious damage occurred on the cold-worked bridge pieces. The fact that this damage was somewhat more severe than that observed even in the surfaceline specimens of Mut No. I well (about two miles away) tends to confirm an earlier hypothesis that conditions responsible for corrosion are more pronounced at the bottoms of the wells.

Mild steel corrosion probes were tried in only two wells of Dakhla Oasis, Maassara No. I and Balat No. 6. The performance was essentially the same in both cases; the first specimen corroding to failure in the short period of 29 days, while the second lasted only 47 days. The steep slopes of their corrosion rate curves, as compared with reference curves in figure 7 , show that the waters of these Figure 7.--Corrosion rate curves, mild steel probes, Dakhla Depression. 
$\stackrel{\text { DIRECTION OF }}{\leftarrow \text { FLOW }} \leftarrow \leftarrow$

เै

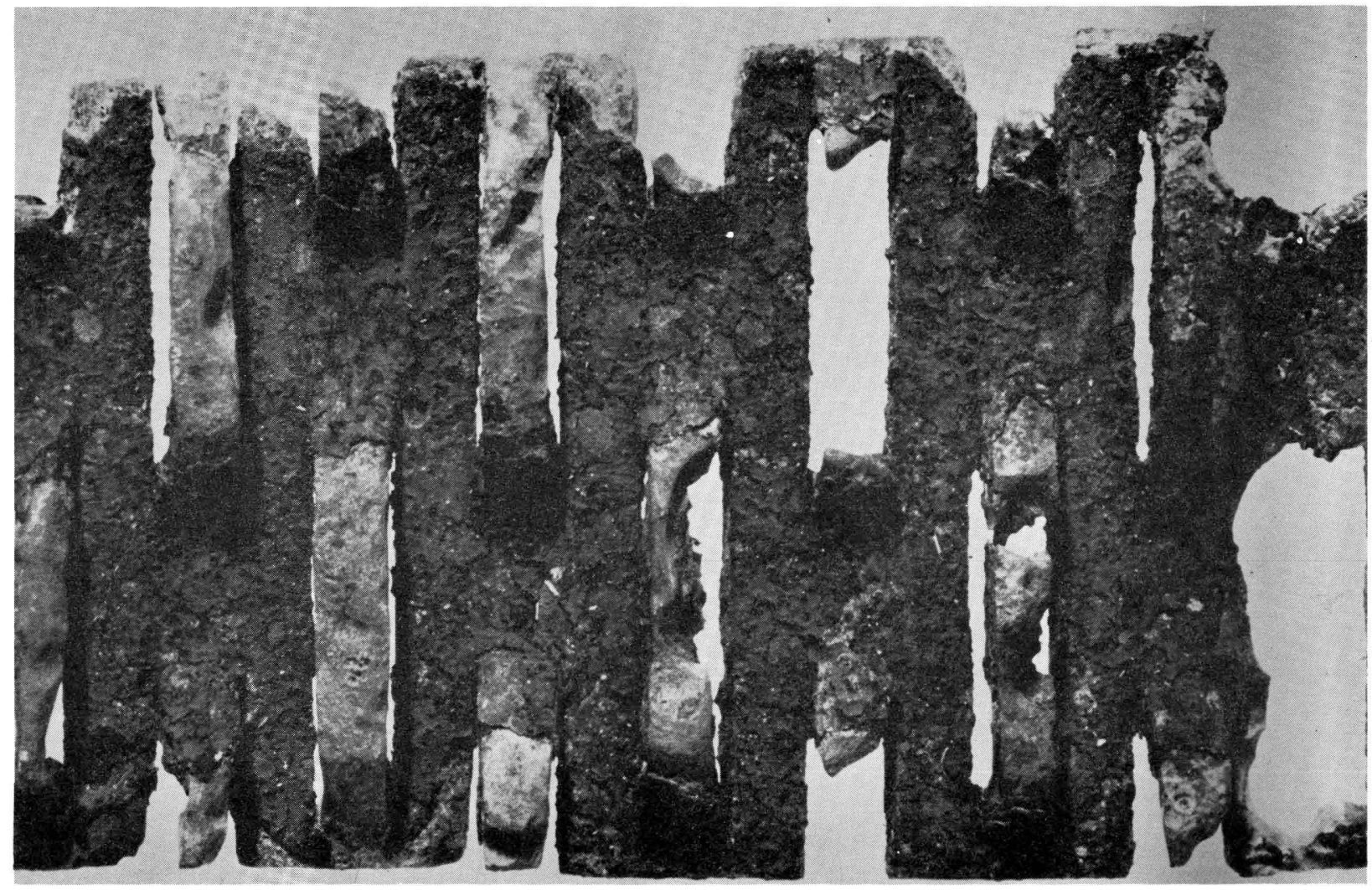

Figure 6.--Steel bottom-hole specimen, 11 months' exposure, Mut No. 2 Well - 1.75X. 


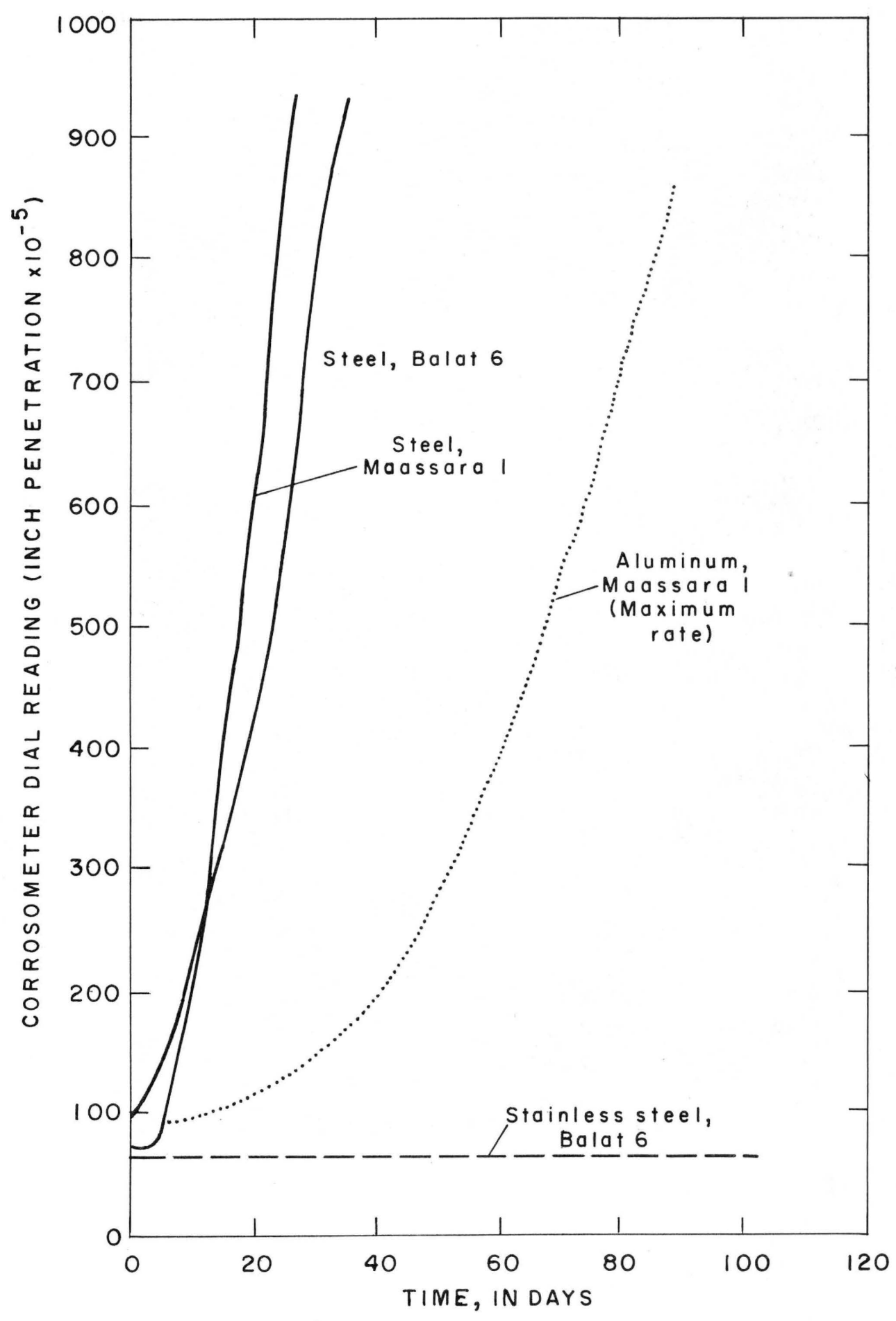

Figure 7.--Corrosion rate curves, mild steel probes Dakhla Depression. 
particular Dakhla Depression wells are far more destructive to mild steel than those tested in Kharga Depression.

Aluminum.--The aluminum bridge-slotted specimen exposed continuously in the discharge line of Mut No. I Well from December 1962 until March 1964 had essentially the same appearance as when it was removed for inspection in May 1963. The surface was speckled with widely-scattered white corrosion tubercles covering shallow corrosion pits from 0.008 to 0.019 -inch depth. In contrast to this excellent performance, wire-wrapped specimens and bridge-slotted specimens of aluminum screen material removed from the bottom-hole specimen string in Mut No. 2 Well (1100 feet below surface) after one year were speckled with white corrosion tubercles over 20-25 percent of their surface areas (fig. 8). Maximum penetration on these specimens was about 0.025 inch, or about 10 percent of wall thickness. The aluminum surfaces between the tubercles and pits were heavily encrusted with black deposits of iron corrosion products which may have contributed to the attack by serving as cathodic surfaces in corrosion cells. $\mathrm{X}$-ray diffraction showed this deposit to be primarily iron oxide.

Figure 8.--Aluminum bottom-hole specimen, Il months' exposure, Mut No. 2 Well - 1.25X.

Both the nature and extent of the aluminum damage in Mut No. 2 Well are puzzling in view of water quality data and excellent performance of aluminum in the surface line of Mut No. 1 Well. The extent of damage was considerably less than that of mild steel in the same 


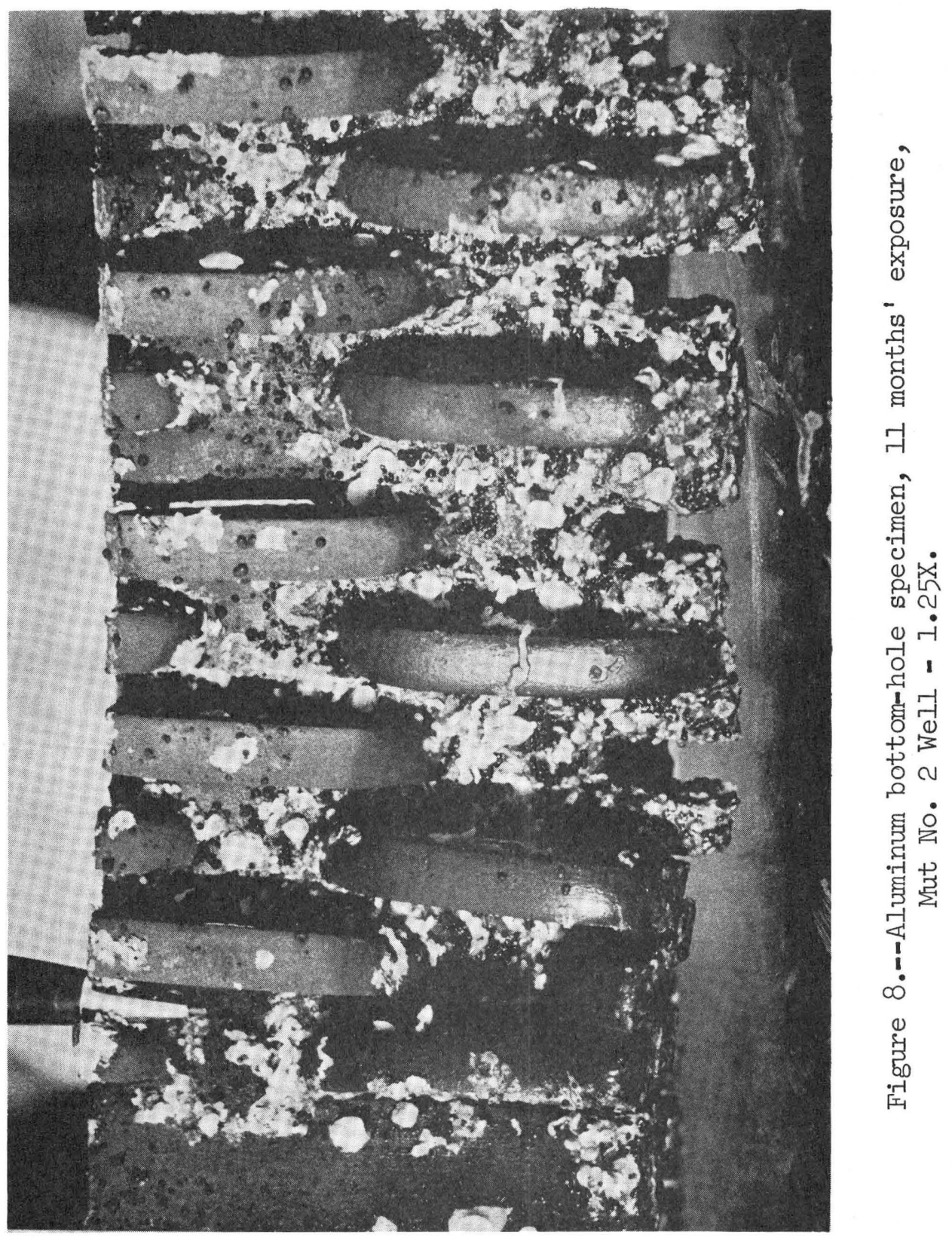


deep-hole location; however, the relatively severe damage to both metals suggests that the deep aquifer water is not properly represented by the mixed surface flow and that it actually is more corrosive than indicated from earlier tests on other Dakhla wells. Unfortunately; the necessity for testing aluminum in the presence of adverse iron corrosion products leaves an element of uncertainty regarding deep-hole performance of aluminum alloy.

Performances of the two aluminum probes exposed in Dakhla wells were quite different. That in Maassara No. 1 Well corroded rapidly to failure in only 89 days; whereas an identical specimen in Maassara No. 3 Well showed practically no increase in corrosion rate after 95 days, when the data were collected for this report. This difference is apparent in the corrosion curves of figure 9. Again, different mixtures Figure 9.--Corrosion rate curves, aluminum probes, Dakhla Depression.

of the several ground waters integrated by the wells may be responsible for the marked variation in performance.

Monel.--Monel was tested in the bottom-hole specimen string of Dakhla's Mut No. 2 Well (cylindrical specimen), and as corrosion probes in the vertical casings of Rashda No. 2 Well and Maassara No. 1 Well. After about one year of exposure, the cylindrical specimen in Mut No. 2 Well showed a blue-gold-brown, mottled, granular surface pattern similar to that normally obtained by metallographic etching processes (fig. 10). Figure 10.--Monel bottom-hole specimen, Mut No. 2 Well, 1.5X. 


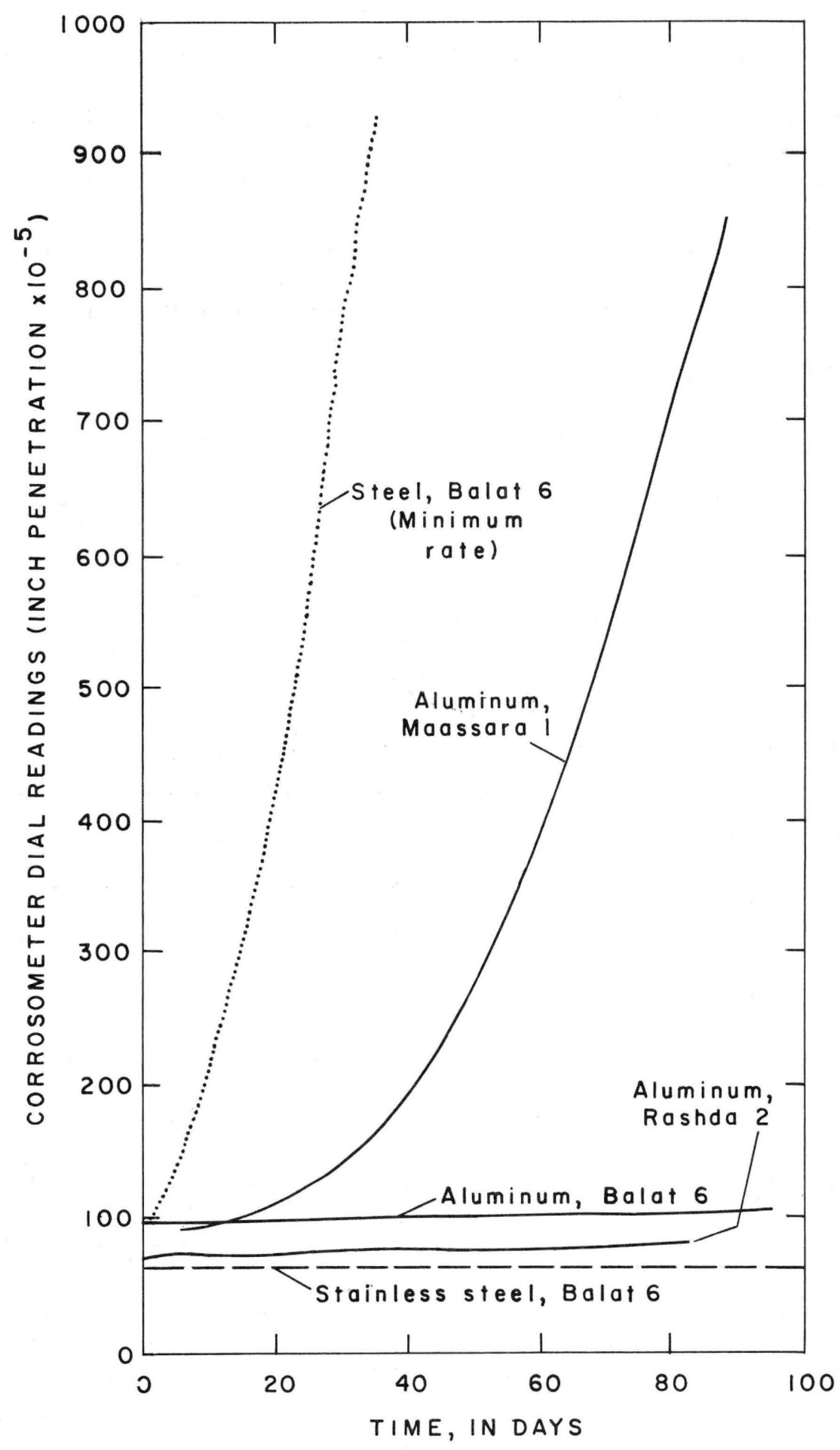

Figure 9.--Corrosion rate curves, aluminum probes, Dakhla Depression. 


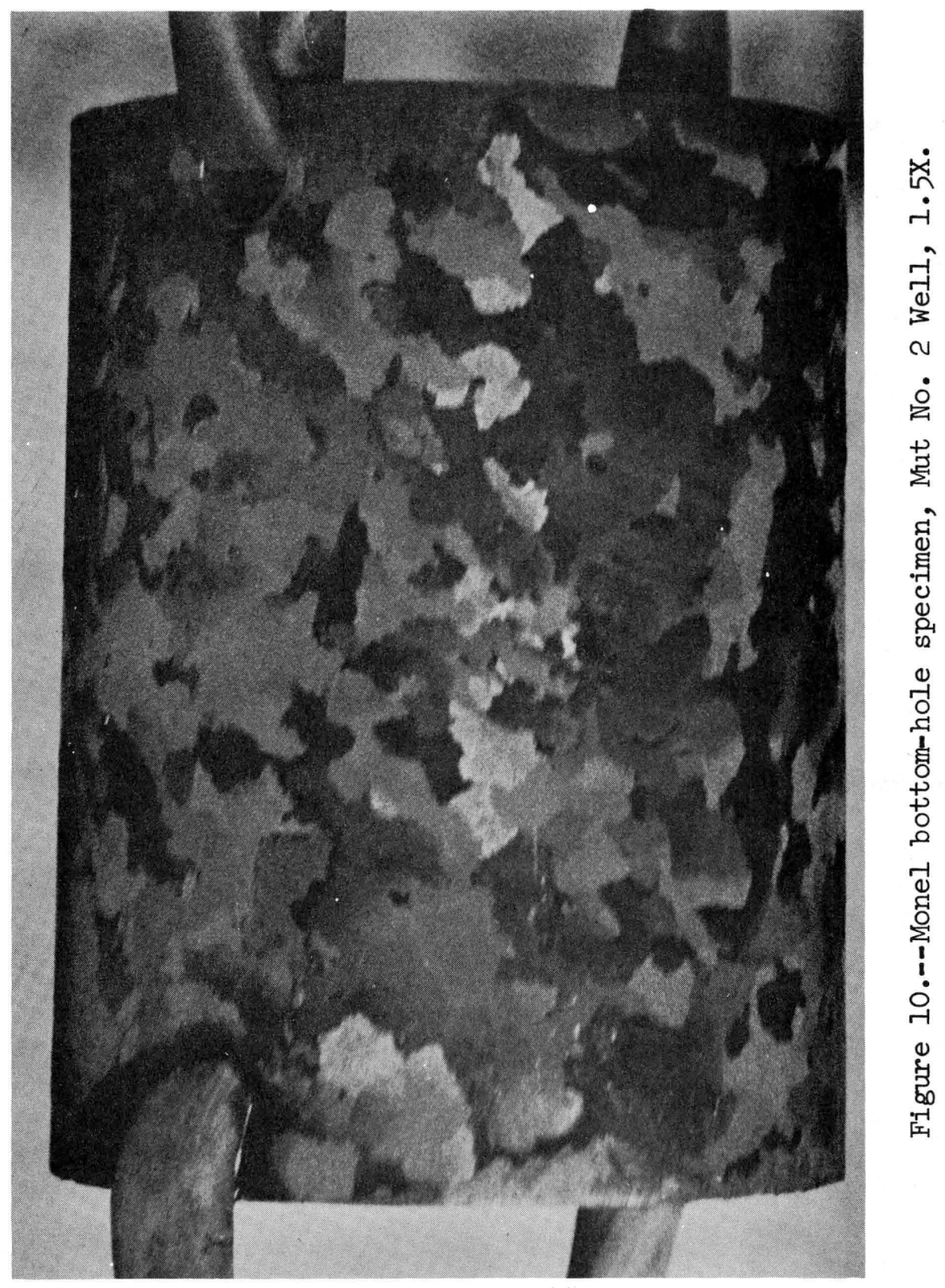


The predominance of golden-brown surface film suggests loss of nickel from the surface. Careful inspection revealed that the surface indeed was wasting away as extremely thin concentric layers. The damage to this specimen was very uniform and the metal loss was relatively insignificant despite the very agressive environment. This, plus the performance of Monel probes in Kharga Depression, suggests that Monel, and perhaps other copper-nickel and conventional copper-bearing alloys (e.g., bronzes), will give reasonably long service. The absence of oxygen depolarization in the anaerobic waters probably explains the lack of severe damage that normally would be expected in the presence of high carbon dioxide content.

The performance of the Monel corrosion probes in Dakhla Depression was similar to that in Kharga Depression. The values obtained for exposures in Maassara No. I Well and Rashda No. 2 Well (0.0003 and 0.0008 ipy respectively) are well within the acceptable range for service installation. They agree with the rather slow attack observed on the bottom-hole Monel specimen in Mut No. 2 Well. The favorable performance of this alloy in both depressions is encouraging, since it suggests that copper-bearing alloys of conventional pumps and valves also may be durable. Confirmation tests have been planned. Stainless steel.--The wire-wrapped stainless steel screen specimen in the discharge line of Mut No. I Well showed only superficial surface film and essentially complete absence of corrosion despite its 2l-month exposure. Cylindrical and wire-wrapped stainless steel specimens from the bottom-hole string in Mut No. 2 Well also were in original condition 
after 11 months of exposure except for the rather heavy brown coating of iron corrosion products mentioned above in connection with aluminum corrosion. These data agree with the consistent observation that stainless steel is virtually unaffected in the waters of both Kharga and Dakhla Depressions, at least to the extent of the testing completed to date.

The corrosion rate curve for stainless steel in Balat No. 6 Well of Dakhla Depression is shown as a reference curve in figure 9. The slope of this curve was essentially zero over the 120 days of test prior to inspection. It will be noted that, while the slope of the rate curve is zero, the actual dial reading (electrical resistance) is higher than that recorded for stainless steel in Kharga Depression (fig. 3). Slight differences in probe wire undoubtedly account for this.

Incoloy 800.--One year of testing in the bottom-hole specimen string of Mut No. 2 Well caused absolutely no damage to this superior alloy. Wiping away its thin brown surface coating showed a mirrorlike finish with no evidence of surface etching or even of persistent tarnish. The corrosion rate curve obtained on an Incoloy probe exposed in Maassara No. I Well agreed with this performance, again showing absolutely no corrosion in the 99 days of exposure prior to inspection. This curve was included in figure 5 . 


\section{Significance of Long-term Corrosion Tests}

These long-term corrosion tests in the Western Desert of Egypt, extending over approximately a two-year period, leave little doubt that mild steel should be avoided in the relatively vulnerable and costly parts of deep-flowing water wells, such as screens and wellhead valves. Only one mild steel specimen (the probe in Nasser No. 3 Well) showed reasonably good resistance to corrosion, and even here the corrosion rate was twice as great as that of an aluminum specimen in the same location. Similar mild steel probes showed rapid deterioration in other wells and in some cases failure occurred in as little as one month (Balat No. 6 Well), indicating an effective corrosion rate of approximately 0.09 inches per year. This is essentially 10 times the corrosion rate which is considered acceptable for mild steel in most service installations.

Surface-line specimens in both Kharga Depression and Dakhla Depression have confirmed the poor resistance of mild steel parts for the service in question, complete penetration of a $\frac{1}{4}$-inch steel casing specimen occurring in as little as four months (Mut No. I Well)(Clarke, 1963). The single test of a bottom-hole specimen (Mut No. 2 Well) showed mild steel to be even less durable at actual screen depth. Discovery of screen bridge pieces in the discharge sump of Kharga No. I Well (Sudrabin, 1962) lends strength to this conclusion. Complete loss of the steel gate in the head valve of Mut No. 2 Well in the short period since its installation further attests to general unsuitability of mild steel parts. 
Use of mild steel in blank casings may be satisfactory if the casings are thoroughly cemented in place, and particularly if the hydrologic studies now under way indicate the probability that the present small-diameter flowing wells are likely to be abandoned in favor of larger-diameter pumping wells in a decade, or thereabout. Since the well heads are readily accessible for replacement, material cost is the principal consideration in their replacement. Therefore, mild steel may prove to be practicable for these components with the exception of the relatively costly and corrosion-sensitive valves. Considered from the standpoint of corrosion alone, aluminum alloys of the type used in this investigation are considerably better than mild steel on the average. Most of the corrosion rate curves and depths of penetration observed on surface specimens suggest that aluminum screens and casings might last several times as long as mild steel in most of the locations tested. Unfortunately, occasional instances of rather poor performance (e.g., aluminum probe in Maassara well) show that substitution of aluminum for steel may not insure improved economy in every location. Lack of specific water quality data for the various water horizons somewhat increases this uncertainty.

Despite the occasional instance of rather rapid attack, there is little doubt that high-strength aluminum would last from 3 to 5 times as long as mild steel in most of the areas tested. To gain greatest 
advantage from this alloy it would be necessary to employ the strongest possible design in the filter section (screen or perforated pipe) to compensate for the fact that the super-aluminum alloys have less strength than steel. The aluminum/steel cost ratio ( 1.5 to 2) shows that there is little economic benefit to be derived from the use of aluminum under the worst conditions observed in these longterm tests (Maassara No. I Well excluded) if only metal costs and metal life are considered. However, the longer life expectancy of aluminum screens would appear to justify their use in any deep artesian wells which are likely to be abandoned in a few years as hydrostatic head declines. While the cost/life-span ratio would be little less than that for mild steel, there would be more assurance of troublefree operation during the expected period of free flow. Work to date suggests that aluminum screens already in use will last until general pumping is required.

When the change is made from flowing wells to pumping, it will be particularly important to install wells with long life expectancies, particularly since there is no evidence of troublesome mineral encrustation problems which might prevent unlimited service from a corrosion-resistant installation. The data thus far do not indicate that aluminum is the best choice for such an operation, although it is better than mild steel. Stainless steel becomes increasingly attractive as the required life span of the well increases. 
The long-term tests also indicate that cast iron probably is not an economically practicable construction material for desert well pumps, and that stainless steel would give long-life pump service. There also is some evidence (from Monel tests) that conventional bronze pump parts would last long enough to justify their use. In view of these observations, it seems logical to start pump tests with a conventional "iron" turbine pump and a similar pump modified for corrosive water service, and to defer testing of relatively costly stainless steel pumps until the practicability of the less durable types has been determined. A conventional iron pump normally is supplied with bronze impellers and Type 316 stainless steel impeller shaft. The column pipe and pump strainer are mild steel. Minimum modifications for corrosive waters generally include substitution of a zincless bronze pump bowl assembly, an organic-coated steel column pipe or one of rigid plastic, and a brass or bronze pump strainer. Ample time should be available to make studies on the two classes before general pumping is required. 
Direction of Future Studies

The observations in Kharga and Dakhla Depressions to date have revealed considerable variation in corrosiveness of desert well waters, particularly as judged from performance of steel and aluminum specimens exposed to integrated flow at the well heads. There also is evidence that corrosiveness of the integrated discharge varies appreciably from that of bottom-hole water in certain of the wells (e.g., Kharga No. la and Mut No. 2). The range of corrosion results thus far obtained makes it reasonably clear which readily-available metals will provide consistently excellent service and which will be relatively good or relatively poor performers on the average. However, the fact that all test metals have not yet been exposed in every test well leaves a void which cannot be bridged safely on the basis of theoretical treatment of the data available.

To provide maximum practicable confirmation of tentative conclusions reached thus far in the study, it is important that wellhead corrosion probe studies be continued until at least mild steel, aluminum and stainless steel have been tried in all of the test wells. It is desirable that similar probe tests be made with zincless bronze (Magna Catalog Everdur 96) and with Incoloy 800 to give a complete set of probe data for correlation with water quality factors. 
It is equally desirable to obtain screen specimen corrosion data (both discharge-line and bottom-hole strings) and to repeat corrosion probe tests in wells which yielded anomalous probe data during original trials (e.g., Nasser No. 1 and Maassara No. I Wells). Surface-line specimens and a complete series of corrosion probes should be tried in Mut No. 2 Well to obtain maximum benefit from the bottom-hole specimen data already obtained there.

For the present, it would be more profitable to complete these "clean-up" tests than to conduct limited corrosion studies (e.g., with one or two probes in other wells of Kharga and Dakhla Depressions). Detailed suggestions are included under "Recommendations."

Since desert well pumps for long-term service probably will be installed in deep wells, and thus will be exposed to a mixture of water from deep and shallow aquifers, the most meaningful pump corrosion data can be obtained by testing experimental pumps in deep wells which pierce as many of the water horizons as is practicable for experimental installations. Mounting the pumps in nonflowing deep wells (e.g., those of Zayat or Kharga) will subject the pumps to mixed supplies of the type likely to be encountered in long-term service. 
Throughout this corrosion study it has been difficult to obtain specific water quality data for various water horizons. This information would be useful in mapping quality patterns. An attempt should be made to study the zones separately in any new well locations in Kharga and Dakhla, and other desert depressions. Much pertinent water quality data can be collected on drill stem samples during drilling operations. Corrosiveness of deep aquifers can best be checked with bottom-hole specimens of the type already used. A limited amount of water-quality data also can be obtained through the use of deep-hole samplers. Well-head corrosion probes and surface-line specimens are adequate for determining effects of mixed discharges from flowing wells. Such data give maximum information regarding probable pump and well-head corrosion.

In every study it is important that a full range of water quality information (including $\mathrm{Eh}$ ) and corrosion test data be obtained for each test well. Partial data often tends to hinder interpretation rather than to facilitate it. The type of equipment, materials and test methods used thus far are adquate, provided the items needed are available in sufficient quantities in the test areas involved. 
Conclusions

The following conclusions are based on the assumption that screening of the desert wells is required to prevent collapse of formations (or to prevent future pump damage) and that the present small-diameter wells will be abandoned when general pumping from below ground level begins, perhaps in a decade, or thereabout. Studies of the need for screening and the probable life of flowing wells were not a part of this program.

1. Mild steel is not a suitable material for constructing screens or filter sections (perforated casings) for wells of Kharga and Dakhla Depressions. It should be adequate for casing deep wells, as formerly concluded, particularly if the casings are well cemented and the present smalldiameter wells are indeed to be abandoned when general pumping begins.

2. Type 304 stainless steel and nickel-chromium alloy (Incoloy 800) are extremely resistant to all desert waters tested to date and should give unlimited service in screens, pumps and other well components wherever the intended service justifies their relatively high initial cost. Stainless has the advantage of lower cost ( $2 \frac{1}{2}$ to 5 times that of mild steel, depending on component design). 
3. From the standpoint of corrosion resistance, high-strength aluminum alloy falls between mild steel and the super-nickel alloys mentioned above. Generally speaking, it should yield from $2 \frac{1}{2}$ to 5 times the service life of steel in the desert wells when used as a screen or perforated filter pipe. Because of its relatively attractive cost ( $1 \frac{1}{2}$ to $2 \frac{1}{2}$ times that of mild steel) aluminum should be practicable for screening any small-diameter wells which are destined to be abandoned on conversion to pumping. The occasional rapid corrosion of an aluminum specimen shows that some risk is involved.

4. The promising performance of nickel-copper alloy (Monel) suggests that conventional zincless bronze will provide economically practicable service in vulnerable, but readily accessible well components, such as pump bowls, pump impellers, and well-head valves. Confirmation tests are needed.

5. Transition to relatively permanent pumping installations will favor use of "noncorrodible" metal screens (or filter pipe), particularly where great depth requires maximum strength of material. However, high-strength nonmetallics, such as epoxyresin-bonded fiberglass discussed earlier (Clarke, 1962 and 1963) should be equally serviceable for pumping wells of shallow depth (e.g., several hundred feet). 


\section{Recommendations}

1. Discontinue the use of mild steel screens and mild steel perforated casing in any wells where screening is required, but continue to use cemented mild steel casing in deep-well sections which are likely to be abandoned when pumping starts.

2. Use Type 304 stainless steel or high-strength corrosionresisting aluminum alloy for filter sections (screens) of these interim small-diameter wells. Make the choice on the basis of initial costs and estimated useful lives of wells which cannot be adapted to pumping. Iong-life expectancy will favor stainless steel, while relatively short life will tend to favor aluminum (see text).

3. Continue water-quality and corrosion-probe tests on all wells thus far included in the program until all pertinent quality data and probe data (mild steel, aluminum, stainless steel and zincless bronze) are available for each. Magna Catalog designation Everdur-96 is a suitable bronze.

4. Install insulated surface-line screen specimens of aluminum, stainless steel and mild steel in the horizontal discharge line of Mut No. 2 Well, to obtain observations for comparison with those obtained on bottom-hole specimens. Use the same kinds of specimens used in Mut No. I Well. Place them in the order given above, with the aluminum nearest the vertical casing. Install an elbow on the end of the discharge line and turn it 
upward to insure continued submergence of the specimens. Flow the well continuously, if practicable, and continue exposure for one year.

5. Make the surface-line tests, and, if possible, the bottom-hole tests described in Recommendation 4, on Nasser No. 1 Well to obtain data for comparison with anomalous corrosion probe data.

6. Repeat the mild steel corrosion-probe test in Nasser No. 3 Well and the aluminum probe test in Maassara No. 1 Well to confirm observed anomalous behavior.

7. Start pump corrosion tests as soon as test pumps now on order arrive, preferably by installing them in deep, nonflowing wells which pierce all of the water horizons likely to be exploited when general pumping begins. Keep accurate records on length and type of pump operation as well as appearance of pump parts during inspections. Inspection of pump impellers, pump bowls and internal and external surfaces of the column pipe at six-month or yearly intervals is particularly important.

8. For all future well development in these and other desert depressions, provide for collecting water-quality data on drill stem samples to obtain specific information on the various water horizons as well as on the mixed flows.

9. Plan and conduct appropriate corrosion tests on other desert depressions as rapidly as possible in order to prepare for well development programs. 


\section{References}

Clarke, F. E., 1962, Evaluation and control of water well corrosion problems in Kharga and Dakhla Oases, Western Desert, Egypt, UAR: U. S. Geol. Survey open file report, $61 \mathrm{p}$.

Clarke, F. E., 1963, Appraisal of corrosion characteristics of Western Desert Well Waters, Egypt: U. S. Geol. Survey open file report, $65 \mathrm{p}$.

Sudrabin, L. P., 1962, Preliminary study of corrosion of deep well casings and screens, Kharga and Dakhla Oases, Western Desert, Egypt, USAID/UAR, Cairo - EGDDO Report. 